\title{
How an OEM Can Become Circular with Remanufacturing: The Case of Robotic Lawn Mowers
}

\author{
Jelena KURILOVA-PALISAITIENE ${ }^{1}$, Johan VOGT DUBERG, Gustav \\ JOHANSSON and Erik SUNDIN
}

\begin{abstract}
Division of Manufacturing Engineering, Department of Management and Engineering, Linköping University, 58183, Sweden
\end{abstract}

\begin{abstract}
The consumption of resources is at an alarmingly high level, and there is a high need for resource-efficient alternatives to manufacturing. Remanufacturing is one way to reduce the use of both materials and energy, while still providing products with a like-new condition. This paper aims to define critical areas to assess when applying remanufacturing to original equipment manufacturers (OEMs). The research was conducted by interweaving remanufacturing's role in a circular economy (CE) with a single case study at a robotic lawn mower OEM. The case study was split into three parts that separately investigated customer demand, product design and economic sustainability, respectively, all in the area of remanufacturing. This paper addressed the research gap in OEM strategy towards a $\mathrm{CE}$ with remanufacturing, defining five critical areas to assess when applying remanufacturing to OEMs: customer, product, sustainability (economic, environmental and social), business model, and production system. The findings of the paper could be useful for many OEMs willing to shift to a CE with remanufacturing.
\end{abstract}

Keywords. Circular economy, circular business models, product life-cycle, remanufacturing, EEE

\section{Introduction}

For the past thirty years, the Swedish manufacturing industry has intensively consumed the country's natural resources $[1,2]$. Dominated by a linear product life-cycle, OEMs generate waste and support resource depletion. To reach resource-efficient manufacturing, a more circular product life-cycle is needed (see [3]). One possible solution to turn a linear product life-cycle to a circular one is to employ remanufacturing.

Remanufacturing is an important part of a Circular Economy (CE), which brings cores (previously used products and their parts) to like-new or better condition $[4,5]$, back into useful life [6] and hence to a state that the next customer is willing to have [7]. It contributes to dramatic savings in raw materials, energy and water resources compared with new product manufacturing [8] and offers business opportunities to various stakeholders within the CE $[5,6]$.

\footnotetext{
${ }^{1}$ Corresponding Author. jelena.kurilova@liu.se
} 
The Swedish remanufacturing industry comprises a small share (less than $1 \%$ ) of the EU remanufacturing sector [9]. Since remanufacturing is limited to a few industries such as heavy vehicles, automotive and IT, Swedish consumers do not have access to a wide range of remanufactured products, and their acceptance has remained low [10]. Applying remanufacturing to OEMs would enable the OEM's shift towards a CE and facilitate consumers' access to and acceptance of a wider range of remanufactured products. However, bringing remanufacturing to the OEMs' strategic level would influence many OEMs' critical decision areas. Therefore, it is important to define which critical areas would be affected when applying remanufacturing to OEMs.

The aim of this research paper is to define critical areas to assess when applying remanufacturing to OEMs.

\section{Research design}

In order to meet the aim of the research paper, the studies on the previous literature on remanufacturing's role in $\mathrm{CE}$, the product lifecycle, drivers and barriers for remanufacturing, and manufacturing strategy were performed. Through a literature study, three areas were identified for analysis at a case company: customer demand, product design and economic sustainability. An analysis of the robotic lawn mower life-cycle and a study on how the case company could become circular with remanufacturing were undertaken.

The survey data from 118 respondents, that correspond to $1 \%$ response rate, was used to study the

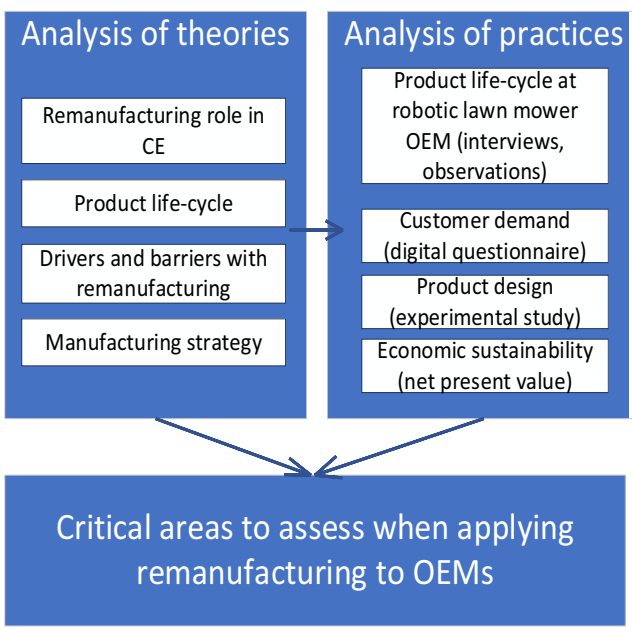

Figure 1. Research process with the analyses of theories and practices which lay a base for the findings of the paper. customer demand. An experimental study of the selected model of a robotic lawn mower was performed, where product disassembly and assembly process were documented. 17 semi-structured interviews with company representatives and its retailers have been accomplished. Three observation of the value retain operations at retailers have been carried out. The net present value of the remanufacturing operations has been calculated to show the effect of remanufacturing to OEM core businesses.

Both the analyses of the theories and practices lay the base for the development of the critical areas to assess when applying remanufacturing to OEMs.

\section{The role of remanufacturing in a circular product life-cycle}

A Circular Economy (CE) can be defined as "restorative and regenerative by design, and which aims to keep products, components and materials at their highest utility and value 
at all times" [11]. The CE aims to reduce the amount of material loss in a product lifecycle and prevent the extraction of virgin and scarce raw materials. Apart from product development, a typical product life-cycle of a technical product in a CE undergoes several phases such as mining and material manufacturing, product manufacturing, retail and service, use, and used product value recovery. There, the embedded value of products is preserved through restorative cycles: first maintenance, followed by reuse/redistribution, then refurbishment/ remanufacturing, and finally, by material recycling [11].

In contrast to a $\mathrm{CE}$, a more traditional linear product life-cycle (see Figure 2) diminishes the OEM's possibility to take responsibility for its product, emphasizing a loss of control over the product in its use phase. The lack of the after-market offerings by OEMs, typically limited to service according to warranty, signals that the majority of OEMs lose their product's value after it is disposed of, creating waste as well as contributing to resource depletion (see also [12]).

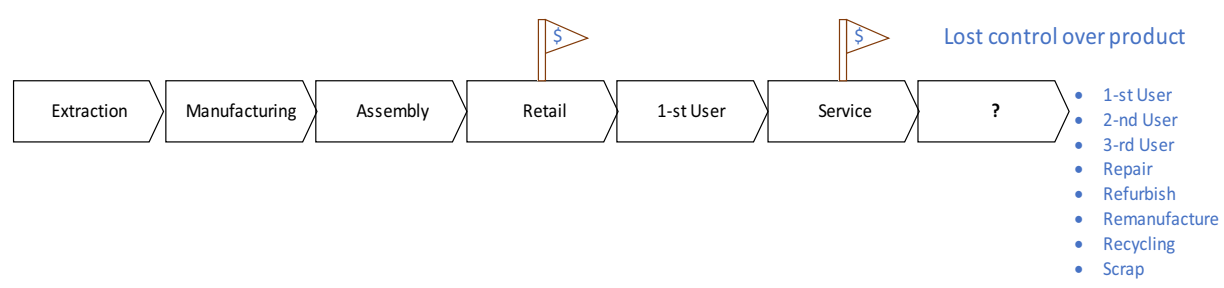

Figure 2. Linear product life-cycle with flags for earnings (adapted from [12]).

To close the material loop in the after-market offering, remanufacturing could be applied. Remanufacturing is an industrial process that consists of several steps, to include control of the arrived core (a product or its part intended for remanufacturing), core disassembly, repair, replacement, assembly and test [13]. The studies performed by Kerr and Ryan [14], Sundin and Tyskeng [15], Lindahl et al. [16], Gell [17], Baustani et al. [18], Goldey et al. [19], and Kara [20] show that remanufacturing is an environmentally beneficial way of closing the flows of products, parts and materials. One reason why remanufacturing is found attractive from an environmental point of view is that the efforts made when manufacturing new parts, e.g., material extraction, material manufacturing, part manufacturing and product manufacturing, are fully or partly salvaged when performing remanufacturing.

Remanufacturing goes along with the 2020 EU legislations for energy use reduction and OEM responsibility to take care of their products long after they have been sold. The regulations, such as Extended Producer Responsibility (EPR), are designed to force producers to take life-cycle responsibility for their products. Therefore, remanufacturing helps to comply with environmental regulations.

By introducing remanufacturing, a greater degree of product control through its lifecycle can be achieved. As shown in Figure 3, by extending the control over the product through remanufacturing, OEMs would gain more earnings from the recaptured product (see also [12]), increased market share, customer loyalty, product knowledge and information on the product performance, as well as benefit from saving on resources such as raw material, energy, and water [8]. Additionally, remanufacturing can broaden 
aftermarket sales offerings through a spare part sale, improve the brand, reduce costs (especially warranty-associated ones), and protect intellectual property [21].

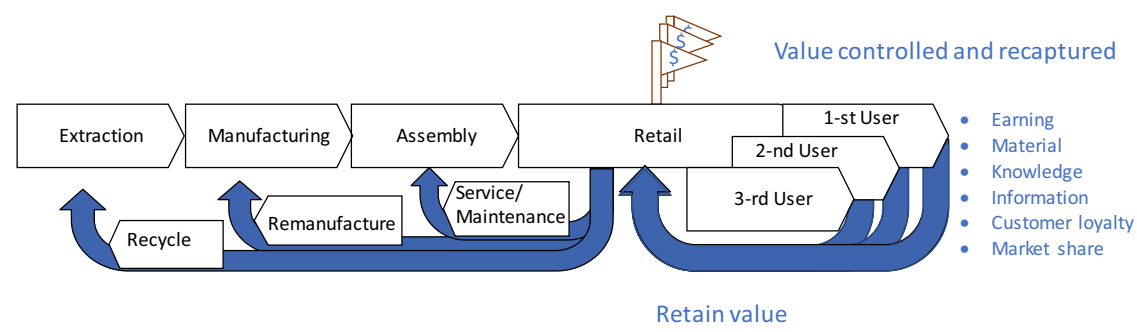

Figure 3. Circular product life-cycle with flags for earnings (adapted from [12]).

However, bringing remanufacturing to OEMs would influence most of their product life-cycle phases. On a strategic OEM level, applying remanufacturing would influence many OEM's critical decision areas. The following sections present the initial areas that need to be assessed in order to apply remanufacturing to an OEM.

\section{Initial areas to assess when applying remanufacturing to OEMs}

There have been several studies on drivers and barriers for remanufacturing companies conducted around the world, e.g., in the USA [22], Japan [23], Europe [9], China [24] and Sweden [25]. Kurilova-Palisaitiene et al. [7] have also studied process challenges in general. Three initial areas, based on the literature analysis (see also Figure 1), were formulated for analysis at the case company:

\subsection{Customer demand}

Businesses require attractive offerings to maintain economically sustainable operations. For remanufacturing, this is important as well. The studies by Sundin et al. [26] and Wang et al. [27] have shown that all products are not perceived the same. Some customers perceive aesthetic attributes, e.g., as the most significant, while others are attracted more to things like features, performance or durability [28]. It was therefore viewed important to investigate whether there would be an interest, or demand, in the remanufactured product of the case company.

\subsection{Product design}

Products are not always designed to be disassembled, making remanufacturing difficult to perform [13]. The second area to investigate, therefore, was the design of the robotic lawn mower. The study focused on how suitable the product is for remanufacturing and what design changes could be made to ease remanufacturing.

\subsection{Economic sustainability}

The study of Yalabik et al. [29] has identified that remanufacturing companies are often more profitable than traditional manufacturers, but as Kovach et al. [30] stated, it could 
turn out to be a mismatch if the market segmentation and pricing are not suitable. A third study, to confirm that there is a potential for profit, was conducted to evaluate the feasibility of a remanufacturing process for the case company. The study investigated the economic aspect and how it could be integrated into the existing product life-cycle.

\section{Robotic lawn mower OEM's product life-cycle}

The robotic lawn mower manufacturer is an OEM located in Sweden. The OEM is also offering forest, lawn and garden products such as lawn mowers, chainsaws, pressure washers and trimmers under the same brand as the robotic lawn mower. During the last five years, the market for the robotic lawn mower and other battery-powered products has, according to the OEM, grown annually by more than $20 \%$. An overview of the case company characteristics is summarized in Table 1.

Table 1. Characteristics of the robotic lawn mower OEM in respect to the remanufacturing market.

\begin{tabular}{ll}
\hline Characteristics & Company \\
\hline Company size & Large \\
\hline Sector & EEE \\
\hline Remanufacturer type & OEM \\
\hline Remanufacturing experience & No \\
\hline $\begin{array}{l}\text { Product complexity (number of components } \\
\text { aimed for remanufacturing) }\end{array}$ & Moderate \\
\hline Remanufactured product price & Moderate \\
\hline
\end{tabular}

The robotic lawn mower is a premium electric and electronic equipment (EEE) product. It is assembled in two manufacturing plants located in Europe. In these factories, most of the plastic articles are produced as well, while the remaining components are sourced from suppliers. The OEM is active on a global market but concentrated mostly on the European and North American. A vast supply chain is used, being a global company, to deliver the products to its customers. From the manufacturing plants, the robotic lawn mower is transported mainly to central warehouses and distribution centers. These warehouses and centers can cover multiple regional markets, such as multiple countries. Thereafter, the robotic lawn mower is transported to the company's retail network. The end customer is reached once the product is purchased from a retailer. In some cases, online ordering is possible, but even then, the end customer is assigned a retailer from which the product can be retrieved.

Only retailers that are specialized in the robotic lawn mower are allowed to sell it; therefore, large retailer chains with a vast range of products without workshops, deep product knowledge or dedicated product support are not included in the retail network.

Regular service is offered at most retailers. In countries with winter seasons, it is also common to offer winter service and storage of the lawn mower. The service offering is supported by the OEM, but it is only offered directly through the retailers. A consequence of this is that, once the warranty of the product runs out, the OEM has no further contact with the robotic lawn mower users. Retailers repair the product on their own initiative to extend the life span, with no direct incentives from the OEM. The retailers sell and use genuine spare parts delivered from the OEM, and thereby the OEM benefits from the performed services and repairs. Once the product is out of use, it is left for recycling. The circular incentive provided by the OEM is a support in how the robotic lawn mower users and retailers should perform service of the lawn mower and how to recycle it. In a similar manner to Figure 2, the OEM follows mostly a linear product life- 
cycle, especially when considering its own operations. As depicted in Figure 4, the OEM does not directly participate in the circular flow between retailers and aftermarket offerings.

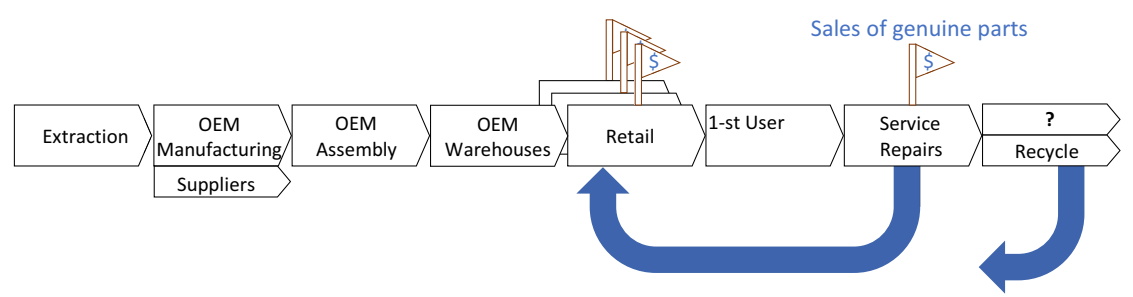

Figure 4. Current robotic lawn mower OEM's product-life cycle (mainly linear).

\section{Robotic lawn mower OEM's shift to a CE with remanufacturing}

As discussed in Section 1, the linear product life-cycle is dominant at OEM manufacturers, which is also the case of the robotic lawn mower OEM. The linear product life-cycle of the studied OEM is mainly dictated by marketing and sales channels. At the same time, shifting towards a CE with remanufacturing is considered, by the case company, a beneficial way to gain a competitive advantage. The initial areas defined in Section 2, were analyzed at the robotic lawn mower OEM:

\subsection{Customer demand}

The robotic lawn mower customers showed an interest in remanufactured robotic lawn mowers. Current customers emphasized the need for more information regarding the conditions and terms of use of the remanufactured robotic lawn mowers well as the points where the product can be obtained. The study identified that remanufactured product performance, durability, serviceability and price advantages are the four underlying factors that consumers value the most. Therefore, customers are willing to buy remanufactured robotic lawn mowers if the price is low, the performance is as a new product, the life span is as promised, and it can easily be maintained and served to prolong the product's life. Additionally, the customers were equally willing to buy from retailers or on the internet with approval from original remanufacturers. For more detail, see Kabel and Ahlstedt [31].

\subsection{Product design}

The study on the design suitability for remanufacturing identified a need for a moderate design improvement to facilitate the remanufacturing process of the company's robotic lawn mowers. The study defined key parts for replacement by new spare parts and the parts that can be recovered during the remanufacturing process. The performed product analysis also revealed a possibility to eliminate certain parts and simplify reassembly through design for remanufacturing (DfRem), for example, by integrating components and selecting different types of fasteners. The analysis of the product from a design 
perspective laid the base for the development of required remanufacturing process steps. For more detail, see Bergstrand and Broman [32].

\subsection{Economic sustainability}

The study on economic sustainability focuses on the profitability assessment, is based on net present values, and confirmed that the remanufacturing of robotic lawn mowers could be profitable for the OEM. Two options to apply remanufacturing to the OEM were assessed with a positive profitability index: 1) the OEM performs remanufacturing at a close distance to its spare parts warehouse, and 2) the OEM delegates the execution of remanufacturing to few larger retailers. The advantages of the centralized option are easy access to spare parts and lower cost due to fewer middle hands. The decentralized option stands for an easier core acquisition from the users and a smoother integration of the remanufacturing process to existing operations in the repair shops at the retail side. This study identified that the robotic lawn mower OEM could gain more benefits by applying remanufacturing to its robotic lawn mowers at a few large OEM retailers.

Additionally, a suggested approach to select appropriate production systems for remanufacturing was developed, as well as the identification of labor, logistics, and operational prerequisite factors. The factors are to be considered when applying remanufacturing for any of the two options. For more detail, see Johansson and Vogt Duberg [33]. Based on the case study, the need to investigate other areas when applying remanufacturing to an OEM were identified as follows: business model; production system, and environmental and social sustainability.

One way for OEM to become more circular is to apply remanufacturing. However, this case study revealed that there was a lack of an OEM strategy towards CE with remanufacturing. The case study also highlighted that the remanufacturing process and the mindset of a CE must be incorporated into the robotic lawn mower OEM's business model. It was also discovered that other aspects, such as expected remanufactured product demand and how to incorporate retailers, will influence the choice of production systems with remanufacturing at the case company.

Based on the findings of the literature review (Section 3) and case study (Section 5), the critical areas for assessment when applying remanufacturing to an OEM are defined in a remanufacturing strategy.

\section{Remanufacturing strategy}

Manufacturing strategy has, for years, been utilized both in academia and industry to analyze and improve the competitiveness of a company through its manufacturing. The modern top-down model with the use of competitive priorities (or manufacturing outputs) originated from Skinner [34] and was later expanded upon with additional focus on production systems [35] and manufacturing decision categories [36, 37]. The six manufacturing decision categories are human resources, process technologies, facilities, sourcing, organizational structure and control, and production planning and control.

OEM strategy cannot be considered directly transferable to sustainable manufacturing, as environmental issues can result in added complexity to the decision factors from both internal and external sources [38]. Therefore, the application of 
remanufacturing to an OEM requires a systematic approach and usually leads to radical changes in many OEM's activities.

The remanufacturing strategy for an OEM intends to complement its manufacturing strategy, as it is defined by Hill [39], Skinner [34] and Wheelwright [40] by facilitating the company's competitiveness through a sustainable approach in its product life-cycle management. Remanufacturing strategy enables a circular flow of material and information by recapturing the lost value of the used product. Based on the findings from the literature review and case study, the remanufacturing strategy is realized through five critical areas: product, customer, sustainability (economic, environmental and social), business model, and production system as presented in Table 2. The five critical areas are further divided to sub-areas, that are also depicted in Figure 5.

Table 2. Origin of critical areas in need of assessment when applying remanufacturing to OEMs

\begin{tabular}{cl}
\hline Critical areas & \multicolumn{1}{c}{ Origin of critical areas } \\
\hline Customer & Lekurwale et al. [36]; Miltenburg [37]; Sundin et al. [41] \\
\hline Product & Lekurwale et al. [36]; Miltenburg [37] \\
\hline \multirow{2}{*}{ Sustainability - Economic } & $\begin{array}{l}\text { Demirel and Gökçen [42]; Fleischmann et al. [43]; Guidat et al. [4]; } \\
\text { Matsumoto and Umeda [23]; Seitz [45] }\end{array}$ \\
\hline \multirow{2}{*}{ Sustainability - Environmental } & Baustani et al. [18]; Gell [17]; Goldey et al. [19]; Guidat et al. [44]; \\
& Kara [20]; Kerr and Ryan [14]; Lindahl et al. [16]; Matsumoto and \\
& Umeda [23]; Seitz [45]; Sundin and Lee [8]; Sundin and Tyskeng \\
& [15]; Sundin et al. [41]; Toffel [46]; Wei et al. [47]; Östlin et al. [21] \\
\hline \multirow{2}{*}{ Sustainability - Social } & Ellen MacArthur Foundation [48]; Murray et al. [49]; Sundin et al. \\
& [41]; Östlin [21] \\
\hline \multirow{2}{*}{ Business model } & Ellen MacArthur Foundation [48]; Lekurwale et al. [36]; Miltenburg \\
& [37]; Murray et al. [49] \\
\hline \multirow{2}{*}{ Production system } & Lekurwale et al. [36]; Miltenburg [37] \\
\hline
\end{tabular}

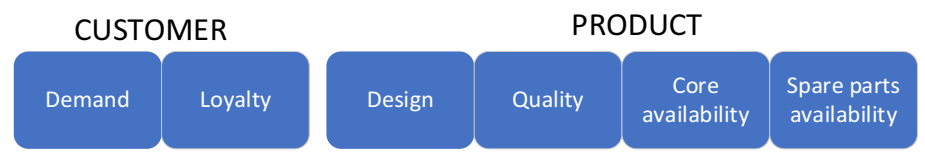

\section{SUSTAINABILITY}
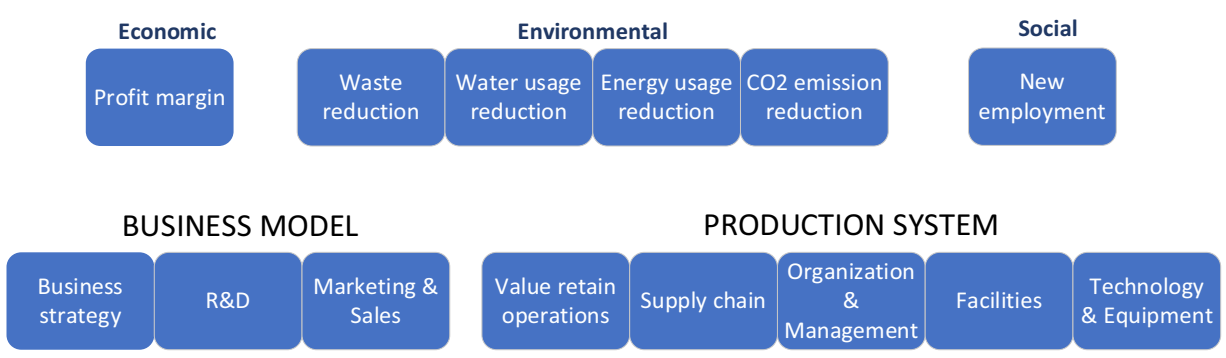

Figure 5. Critical areas and sub-areas to assess when applying remanufacturing to OEMs.

Customer refers to the remanufacturer's connections to the market. Demand deals with the customer's attitude towards a remanufactured product and the willingness and 
need to acquire the remanufactured product. Loyalty covers the customer's openness and commitment to the remanufacturer.

Product are factors governing the suitability of the product for remanufacturing. Design for remanufacturing influences the product's serviceability and the complexity of the remanufacturing process, as well as the ability to transport the product throughout the remanufacturing process, depending on its size and shape. Quality covers the durability of the product and its spare parts and the remaining value of a returning core. Core availability covers the number of cores in circulation and the condition of these cores. Spare parts availability represents the proximity and quality of replacement parts.

Due to the increased focus on environmental issues both in science and the media, and the great importance of these issues, sustainability factors were put into their own standalone categories as to elevate and distinguish their importance to $\mathrm{CE}$ and a remanufacturing implementation.

Economic sustainability denotes the economic motivators for remanufacturing. Profit margin exemplifies the economic value and importance of remanufacturing for the business.

Environmental sustainability refers to environmental motivators for remanufacturing. Waste reduction measures the scrap and rejects produced from the remanufacturer, as well as the input of recycled materials into manufacturing. Water usage reduction controls the water consumption of the remanufacturer. Energy usage reduction checks the energy consumption of the remanufacturer. $\mathrm{CO}_{2}$ emission reduction measures the environmental impact of the remanufacturer in terms of $\mathrm{CO}_{2}$.

Social sustainability is the social motivator for remanufacturing. New employment exemplifies the increased job opportunities added with the incorporation of a return flow to an OEM's supply chain.

Business model refers to key strategic decision making. Business strategy covers how the handling of cores and remanufactured products is performed, reflecting on the circular or linear business models. Research \& Development $(R \& D)$ measures the ability to develop and move towards modern solutions and new avenues of business. Marketing \& Sales represents the efforts to attract external stakeholders and customers to the business model.

Production system includes most of the factors necessary for a remanufacturing system to function effectively. Value retain operations encompasses the OEM operations within service, maintenance, refurbishment, remanufacturing or recycling. Supply chain handles the connections and distances between the remanufacturer, its suppliers, and its market. Organization \& Management is a sub-category which encompasses feedback and organizational goals as well as labor knowledge and capacity. Facilities include the space and property currently available for the remanufacturing process, as well as possibilities of procurement if needed. Technology \& Equipment represents the same in both available equipment and its suitability for the remanufacturing process, as well as opportunities for procurement of such equipment (see Figure 5).

\section{Discussion}

Based on the circular or linear product life-cycle (Figures 2 and 3 correspondingly), the remanufacturing strategy would have different access points and impact on the manufacturing strategy. Several issues needed to be considered when applying remanufacturing to OEMs: 1) Remanufacturing is much more complex than 
manufacturing due to a high number of uncertainties related to core quality, quantity and timing $[25,50,51,52]$. 2) The issues of insufficient core quality and quantity are supplemented by the lack of information on core condition and timing at the previous user. 3) Additionally, remanufacturing maintains lower product volumes, higher product variation, and a higher level of inventory and manual work when compared to manufacturing $[4,50,52]$. Lean remanufacturing is a useful improvement strategy to address these issues (for more detail, see Kurilova-Palisaitiene [7]).

As remanufacturing is becoming a more common activity for OEMs to consider, either performed by themselves of by contracting other companies to performed it, also their remanufacturing strategy needs to get more attention.

\section{Conclusions}

The growing trend towards CE pulls many OEMs to close the material loop through remanufacturing. A novel concept of remanufacturing strategy is formulated to expand upon the traditional manufacturing strategy and reflect on its shift towards a CE.

Through the example of a robotic lawn mower OEM, this paper demonstrates how an OEM can become circular with remanufacturing. Finally, this paper contributes with five areas and their sub-areas that are necessary to assess when applying remanufacturing to an OEM. These critical areas are customer, product, sustainability (economic, environmental, social), business model, and production system.

Future research on the defined critical areas and their sub-areas is needed to validate the findings of the paper and identify new critical areas or sub-areas, for example, through case studies on multiple different industrial sectors and nationalities. The development of a framework or roadmap of how to apply remanufacturing to an OEM, how to assess and in which way to affect critical areas in order to facilitate remanufacturing is within the scope of future research.

\section{Acknowledgement}

The authors would like to thank the Swedish Governmental Agency for Innovation Systems (VINNOVA) for financing the research for this paper through the ElevatoRE project (2018-00330) which was performed within the Challenge-Driven Innovation (UDI) program.

\section{References}

[1] M. Wackernage, L. Lewan and C. Borgström Hansson, Evaluating the Use of Natural Capital with the Ecological Footprint: Applications in Sweden and Subregions, AMBIO, vol. 28(7), 1999, pp. 604-612.

[2] Eurostat report on waste generation by manufacturing industry, 2019, Accessed: 29.11.2019. [Online]. Available: http://appsso.eurostat.ec.europa.eu/nui/submitViewTableAction.do

[3] Manifesto for a Resource Efficient Europe, 2012, Accessed: 29.11.2019. [Online]. Available: http://europa.eu/rapid/press-release_MEMO-12-989_en.html

[4] R. Steinhilper, Remanufacturing - The Ultimate Form of Recycling, Fraunhofer IRB Verlag, 1998.

[5] J. Östlin, E. Sundin, and M. Björkman, Business Drivers for Remanufacturing. In: LCE 2008: 15th CIRP International Conference on Life Cycle Engineering: Conference Proceedings, The University of New South Wales, Sydney, Australia, 17-19 March 2008, pp. 581-586. 
[6] All-Party Parliamentary Sustainable Resource Group (APSRG), 2014, Remanufacturing: Towards a Resource Efficient Economy, pp. 1-12, [Online]. Available: https://www.policyconnect.org.uk/apsrg/research/report-remanufacturing-towards-resource-efficienteconomy-0

[7] J. Kurilova-Palisaitiene, E. Sundin and B. Poksinska, Remanufacturing challenges and possible lean improvements, Journal of Cleaner Production, vol. 172, 2018, pp. 3225-3236.

[8] E. Sundin and H. Lee, In what way is remanufacturing good for the environment? In: Proceedings of the 7th International Symposium on Environmentally Conscious Design and Inverse Manufacturing (EcoDesign-11), Kyoto, Japan, 2011.

[9] D. Parker, K. Riley, S. Robinson, H. Symington, J. Tewson, K. Jansson, S. Ramkumar, and D. Peck, ERN-European Remanufacturing Network, 2015, Remanufacturing Market Study, European Remanufacturing Council, Delft, The Netherlands, Accessed 29.11.2019. [Online]. Available: http://www.remanufacturing.eu/assets/pdfs/remanufacturing-market-study.pdf

[10] E. Sundin, O. Tang, and E. Mårtén, The Swedish Remanufacturing Industry An Overview of Present Status and Future Potential, Proceedings of CIRP Life Cycle Engineering Seminar -12th edition, Paper BM4 on the LCE-05 CD, Laboratoire 3S, Grenoble, France, April 3-5, 2005.

[11] Ellen MacArthur Foundation, Towards the Circular Economy, In: Economic and Business Rationale for an Accelerated Transition, vol. 1, 2013.

[12] A. Fischer and E. Achterberg, Create a Financeable Circular Business in 10 Steps, Circle Economy \& Sustainable Finance Lab, Holland. Accessed 29.11.2019. [Online]. Available: https://www.circleeconomy.com/wp-content/uploads/2016/12/finance-white-paper-20161207-EN.pdf

[13] E. Sundin, Product and process design for successful remanufacturing, Doctoral dissertation, Linköping University Electronic Press, Linköping, 2004.

[14] W. Kerr and C. Ryan, Eco-efficiency gains from remanufacturing: A case study of photocopier remanufacturing at Fuji Xerox Australia. Journal of Clearer Production, vol. 9, 2001, pp. 75-81.

[15] E. Sundin and S. Tyskeng, Inverse Manufacturing at Electrolux or Recycling at Local Facilities? -A Comparison from Environmental and Economic Perspectives, In: Proceedings of EcoDesign 2003, Tokyo, Japan, 2003.

[16] M. Lindahl, E. Sundin and J. Östlin, Environmental Issues within the Remanufacturing Industry, In: CIRP International Conference on Life Cycle Engineering, Leuven, Belgium, 2006, pp. 447-452.

[17] M. Gell, Carbon Footprints and Ecodesign of Toner Cartridges, UK: Xanfeon Energy \& Environmental Services, 2008.

[18] A. Baustani, S. Sahni, S.-C. Graves and T.-G. Gutowski, Appliances Remanufacturing and Life Cycle Energy and Economic Savings, In: The International Symposium on Sustainable Systems and Technology (ISSST), 2010.

[19] C.-L. Goldey, E.-U. Kuester, R. Mummert, T.-A. Okrasinski, D. Olson and W.-J. Schaeffer, Lifecycle assessment of the environmental benefits of remanufactured telecommunications product within a "green" supply chain, In: Sustainable Systems and Technology (ISSST), 2010 IEEE International Symposium, 2010, pp. 1-6.

[20] H. Kara, Comparative Carbon Footprint Analysis of New and Remanufactured Inkjet Cartridges, Center for Remanufacturing and Reuse, 2010.

[21] J. Östlin, On remanufacturing systems: analysing and managing material flows and remanufacturing processes, Doctoral dissertation, Institutionen för ekonomisk och industriell utveckling, Linköping, 2008.

[22] R. Lund, Remanufacturing: The Experience of the United States and Implications for Developing Countries, The World Bank, Washington D.C., 1983.

[23] M. Matsumoto and Y. Umeda, An Analysis of Remanufacturing Practices in Japan, Journal of Remanufacturing, vol. 1(1), 2011, pp. 1-11.

[24] S. Wei, D. Cheng, E. Sundin and O. Tang, Motives and barriers of the remanufacturing industry in China, Journal of Cleaner Production, vol. 94, 2015, pp. 340-351.

[25] P. Lundmark, E. Sundin and M. Björkman, Industrial Challenges within the Remanufacturing System, In: Proceedings of Swedish Production Symposium, ISBN: 978-91-633-6006-0, Göteborg, Sweden, 2-3 December 2009, pp. 132-138.

[26] E. Sundin, J. Östlin and M. Björkman, Why is remanufacturing more successful in the united states than in Sweden, In: CIRP International Conference on Life Cycle Engineering, 2008, pp. 247-251.

[27] Y. Wang, B.-T. Hazen and D.-A. Mollenkopf, Consumer value considerations and adoption of remanufactured products in closed-loop supply chains, Industrial Management \& Data Systems, vol. $118(2), 2017$, pp.480-498.

[28] B.-T. Hazen, C.-A. Boone and Y. Wang, Perceived quality of remanufactured products: construct and measure development, Journal of Cleaner Production, vol. 142, 2017, pp. 716-726.

[29] B. Yalabik, D. Chhajed and N.-C. Petruzzi, Product and sales contract design in remanufacturing, International Journal of Production Economics, vol. 154, 2013, pp. 299-312. 
[30] J.-J. Kovach, A. Atasu and S. Banerjee, Salesforce Incentives and Remanufacturing, Production \& Operations Management, vol. 27(3), 2018, pp. 516-530.

[31] D. Kabel and S. Ahlstedt, Consumer purchase intention of remanufactured EEE products, Master's thesis, Linköping University, Linköping, 2019.

[32] O. Bergstrand and T. Broman, Analysis of the design of a robotic lawnmower from a remanufacturing perspective, Bachelor's thesis, Linköping University, Linköping, 2019.

[33] G. Johansson and J. Vogt Duberg, Economic Potential for Remanufacturing of Robotic Lawn Mowers with an Existent Forward Supply Chain, Master's thesis, Linköping University, Linköping, 2019.

[34] W. Skinner, Manufacturing - Missing link in corporate strategy, Harvard Business Review, vol. 47(3), 1969, pp. 136-145.

[35] J. Miltenburg, Manufacturing strategy: How to formulate and implement a winning plan, Productivity press, New York, 2005.

[36] R.-R. Lekurwale, M.-M. Akarte and D.-N. Raut, Framework to evaluate manufacturing capability using analytical hierarchy process, International Journal of Advanced Manufacturing Technology, vol. 76, 2015, pp. 565-576.

[37] J. Miltenburg, Setting manufacturing strategy for a factory-within-a-factory, International Journal of Production Economics, vol. 113(1), 2008, pp. 307-323.

[38] G. Johansson and M. Winroth, Introducing environmental concern in manufacturing strategies: implications for the decision criteria, Management Research Review, 33(9), 2010, pp. 877-899.

[39] T.-J. Hill, Manufacturing's Strategic Role, The Journal of the Operational Research Society, vol. 34(9), 1983 , pp. 853-860.

[40] S.-C. Wheelwright, Manufacturing Strategy: Defining the Missing Link, Strategic Management Journal, vol. 5(1), 1984, pp. 77-91.

[41] E. Sundin, T. Sakao, M. Lindahl, C. Kao, B. Joungerious and W. Ijomah, Map of Remanufacturing Business Model Landscape, Report from the Horizon 2020 project called ERN - European Remanufacturing Network, Grant Agreement No 645984, 2016.

[42] N.-Ö. Demirel and H. Gökçen, A mixed integer programming model for remanufacturing in reverse logistics environment, The International Journal of Advanced Manufacturing Technology, vol. 39(1112), 2008, pp. 1197-1206.

[43] M. Fleischmann, R.-H. Krikke, R. Dekker and S.-D.-P. Flapper, A characterisation of logistics networks for product recovery, Omega, vol. 28(6), 2000, pp. 653-666.

[44] T. Guidat, M. Uoti, H. Tonteri and T. Määttä, A classification of remanufacturing networks in Europe and their influence on new entrants, In: Procedia CIRP, vol. 26, 2015, pp. 683-688.

[45] M.-A. Seitz, A critical assessment of motives for product recovery: the case of engine remanufacturing, Journal of Cleaner Production, vol. 15(11-12), 2007, pp. 1147-1157.

[46] M.-W. Toffel, Strategic Management of Product Recovery, California Management Review, vol. 46(2), 2004, pp. 120-141.

[47] S. Wei, O. Tang and E. Sundin, Core (product) Acquisition Management for remanfuacturing: a review, Journal of Remanufacturing, vol. 5(4), 2015, pp. 1-27.

[48] Ellen MacArthur Foundation, What is a Circular Economy?, 2017, Accessed: 22.01.2019. [Online] Available: https://www.ellenmacarthurfoundation.org/circular-economy/concept

[49] A. Murray, K. Skene and K. Haynes, The circular economy: An interdisciplinary exploration of the concept and application in a global context, Journal of Business Ethics, vol. 140(3), 2017, pp. 369-380.

[50] V.D.R. Guide Jr., Production planning and control for remanufacturing: Industry practice and research needs, Journal of Operations Management, vol. 18(4), 2000, pp. 467-483.

[51] T. Sakao and E. Sundin, How to Improve Remanufacturing? - A Systematic Analysis of Practices and Theories, Journal of manufacturing science and engineering, 141(2), 2019, 021004.

[52] M.-A. Seitz and K. Peattie, Meeting the closed-loop challenge: The case of remanufacturing, California Management Review, vol. 46 (2), 2004, pp. 74-89. 